\title{
Evaluation of Ventral Dartos Fascia Flap as a Covering Layer in TIP (Tubularized Incised Plate) Repair for Distal Hypospadias Patients [Snodgrass Technique] \\ E.M.Kilany ${ }^{1}$, G.I.El-Habba ${ }^{2}$, E.M.Oraby ${ }^{3}$, M.I.Abo Rizk ${ }^{1}$, A.J.El-Nasseh ${ }^{1}$ \\ ${ }^{1}$ General Surgery Dept., Faculty of Medicine, Benha Univ., Benha, Egypt \\ ${ }^{2}$ General Surgery, Plastic Surgery Dept., Faculty of Medicine, Benha Univ., Benha, Egypt \\ ${ }^{3}$ General Surgery,Pediatric Surgery Dept., Faculty of Medicine, Benha Univ., Benha, Egypt
}

\begin{abstract}
Hypospadias is one of the most frequent congenital urological anomalies. Reports have suggested that the prevalence of hypospadias varies across different races, being highest among Caucasians, less in Hispanics, and least in blacks usually it occurring in 1-3 per 1,000 live births. The different degrees of hypospadias require different technique; which carry different complication rates and different prognoses. The aim of this study is to evaluate the outcome and efficiency of Ventral Dartos Fascia Flap as a covering layer in TIP [Tubularized Incised Plate] Repair for Distal Hypospadias Patients. Twenty-three patients with distal hypospadias was involved in this study. The Snodgrass technique was done to them using ventral Dartos fascia flap as a covering layer in this surgery. the risk of the fistula is about $4.3 \%$, and the cosmetic appearance was so acceptable in 22 patient out of 23 which is very convincing result from this simple technique. Glans dehiscence hadn't occur, Meatal stenosis hadn't occur, Skin infection occurred in one patient because he neglect the postoperative follow up visits and bad hygiene so the wound was moisture and infected, Edema, Inflammation and Encrustations. Urethral Stricture wasn't reported in this study. Twisting of the penis is not reported in this study. TIP repair is a good procedure with no more complications than other procedures used in hypospadias surgery which can achieve both results, restore good function and normal appearance to the penis.
\end{abstract}

E-Mail:amgad@gmail.com

Keywords: Dartos Fascia, Flap, TIP, Hypospadias, Snodgrass Technique.

\section{Introduction}

Hypospadias is one of the most common congenital malformations in male newborns, its incidence about $1: 300$. Hypospadias is an anomaly involving the ventral aspect of the penis; which includes an abnormal ventral opening of the urethral meatus, an abnormal ventral curvature of the penis (known as chordee) and sometimes an abnormal distribution of the foreskin. Surgical treatment is necessary and more than 300 operation techniques have been described for primary hypospadias, whoever the ultimate goal of hypospadias surgery is to create a normal looking penis with a terminally situated conical meatus, correct chordee if present and to ensure a well-directed, straight, and full urinary stream in the standing position [1].

In hypospadias the ventral axis of the penis is deficient; not only is the ventral side of the urethra missing, but also the Spongious tissue and fibrous bands replace Buck's fascia and the Dartos fascia The borders of the foreskin are displaced laterally creating the dorsal hooded prepuce. In most reconstructive techniques the redundant dorsal skin is used to compensate the deficient ventral skin. The Snodgrass technique, or tubularized incised plate (TIP) urethroplasty, is a single-stage, simple surgical technique with good cosmetic results and a low complication rate. Surgical reconstruction is the only possible therapeutic option for hypospadias [2].

The complication rate varies with the complexity of the repair and the surgeon's experience level. The most common complications include fistulae, urethral stricture, meatal stenosis, persistent chordee, infections, and wound dehiscence [3].

The aim of this study is to evaluate the outcome and efficiency of Ventral Dartos Fascia Flap as a covering layer in TIP [Tubularized Incised Plate] Repair for Distal Hypospadias Patients.

\section{Patients and methods}

This prospective study was conducted in General surgery department Of Benha university hospital after an approval from the research ethics committee in Benha faculty of medicine and all patients had sign informed consent that they would been involved in this study Twenty-three patients with distal hypospadias was involved in this study. The Snodgrass technique was done to them using ventral Dartos fascia flap as a covering layer in this surgery.

\subsection{Ethical committee}

This study had both academic and practical targets. Every child was included in this study after making discussion with his parents and taking informed consent.

The study was done from May 2018 to November 2020. All patients in this study were submitted to full clinical examination, and preoperative investigations in the form of urine analysis, CBC, liver function testes and coagulation profile. The operations done in Egypt (Benha University Hospital). Patient age ranged from 18 months to 10 years (mean age $34.8 \pm 9$ months). Meatal position was coronal or distal shaft $(\mathrm{n}=28)$

Inclusion criteria:

All patients with primary distal hypospadias and with no chordee, (coronal, sub coronal, distal penile).

\section{Exclusion criteria \\ Recurrent cases. \\ - Patients with severe chordee. \\ - Adult cases.}




\subsection{The operative technique}

1- Sterilization with proper cleaning of the penis and through the surgical field (from the umbilicus to the knee joint).

2- Examination of the penis and glanular tilt.

3- Marking the incision line $(1 \mathrm{~cm}$ below the external meatus at ventral side $\& 5 \mathrm{~mm}$ below the glans at dorsal side) with a marking pen.

4- Measuring the width of the glans \& urethral plate Fig (1).

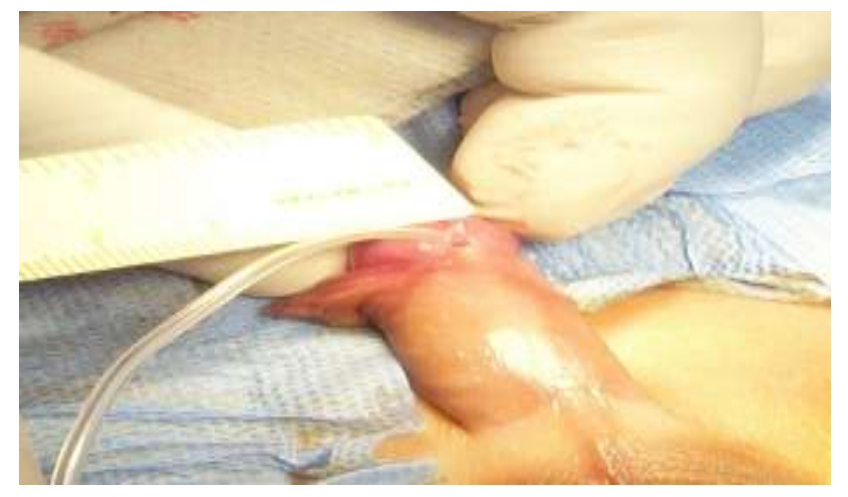

Fig (1) Measuring the width of the glans and urethral plate.

1. A 5-0 polyprolene stay suture is taken at the tip of the glans to work as a stay suture and to fix the urethral catheter if it will be left in place

2. A skin incision extended from the corners of the dorsal preputial hood to $1 \mathrm{~cm}$ below to the meatus and dorsally $5 \mathrm{~mm}$ below the coronal sulcus .

3. Complete degloving of the penis was performed; artificial erection method was done to confirm absence of ventral curvature (Fig 2).

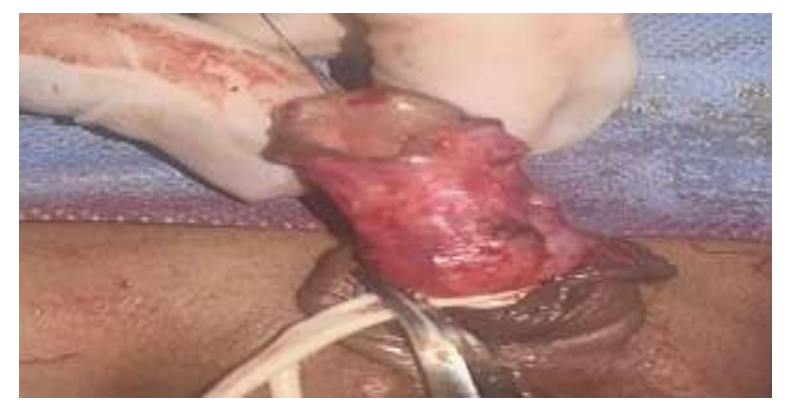

Fig (2) Complete degloving of the penis and Tourniquet around the base of the penis.

4- Regarding intra-operative bleeding it was controllable by injection of 1:150,000 epinephrine and using tourniquet at the base of the penis and sometime controlled by using bipolar cautery. A tourniquet was used around the base of the penis for hemostasis Fig (2).

5- Longitudinal incisions were made along the visible junction of the glans wings to the urethral plate.
6- A mid line incision was made in the midline of the urethral plate by a scissor .

7- The extent of the relaxing mid line incision, deep in the plate till the corpora then proximally from the base of the meatus and distally to the tip of the urethral plate

8-The relaxing incision was made within from the meatus to the tip of the urethral plate. The depth of the incision is deep in the urethral plate till the corpora .

9- A suitable Nelaton catheter (usually 8 fr) was passed into the urethra to the bladder and the tubularization begins over it.

10- First stitch is placed distally opposite midglans, full thickness to keep the external urethral meatus oval shape and wide enough to guard against external meatal stenosis. Then runs proximally in the subepithelial plane till full tubularization, and then runs distally in another layer.

Tubularization done by a running subepithelial closure, turning all epithelium into the neourethral lumen Fig (3). Regarding type of sutures used during the operation, 6/0 vicryl used for internal suture and 6/0 monocryl suture for the skin closure to avoid possible skin tracks.

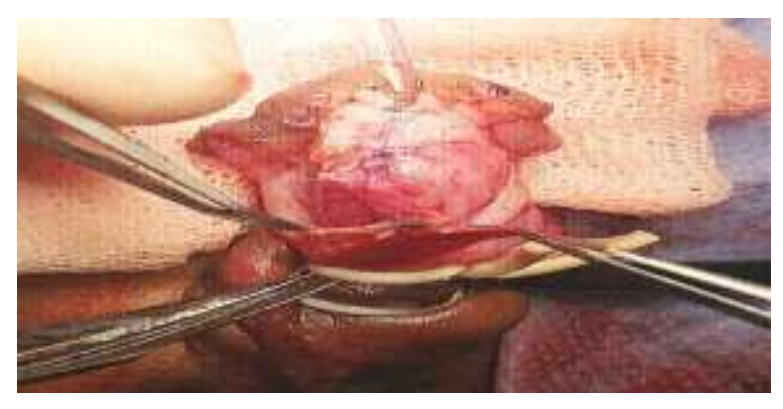

Fig (3) The Tubularization (neourethra).

13- Spongioplasty was done (closure of the fanning shape corpus spongiosum over the neo-urethra).

14- A dartos flap was taken from the ventral skin of the shaft to cover neo urethra Fig.4 (A,B).

\section{Dissection of the ventral dartos fascia Fig 4(A,B)}

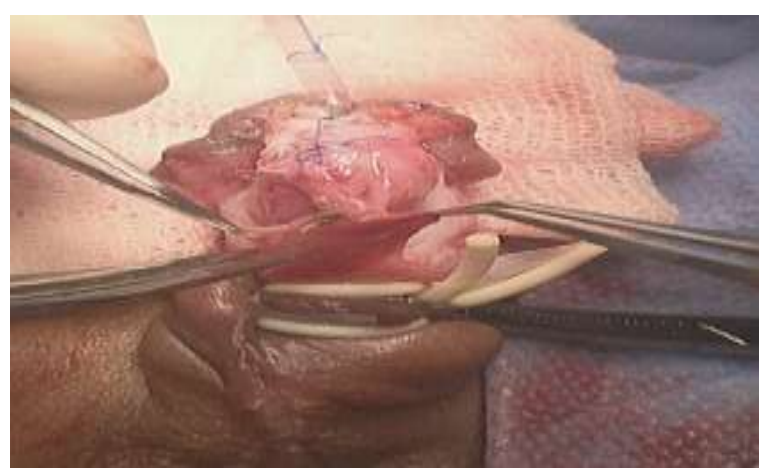

Fig. 4A 


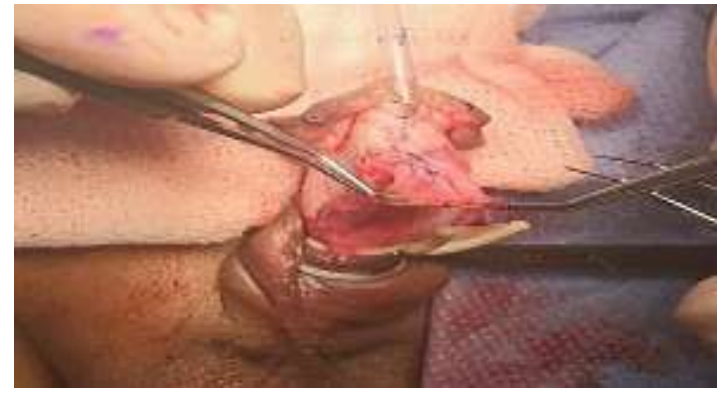

Fig.4B

15-Glanuplasty in one layer by 4 stitches : $1^{\text {st }}$ stitch is the distal one, opposite midglans including full thickness, $2^{\text {nd }}$ stitch is subepithelial at the same level of the $1^{\text {st }}$ one, $3^{\text {rd }}$ stitch subepithelial ,hooking the dartos flap , $4^{\text {th }}$ stitch subepithelial at corona level . Glanuplasty is the main step to achieve the final cosmetic result with No attempt to secure the glans to the underlying neourethra at the external meatus to avoid external meatal stenosis .

16- Skin closures was done using all through $6 / 0$ monocryl sutures to minimize the risk of suture tracks or fistula.

\subsection{The postoperative care}

Post-operative treatment:

- I.V Cephalosporin's 3rd generation (cefotaxime) for first 2 days.

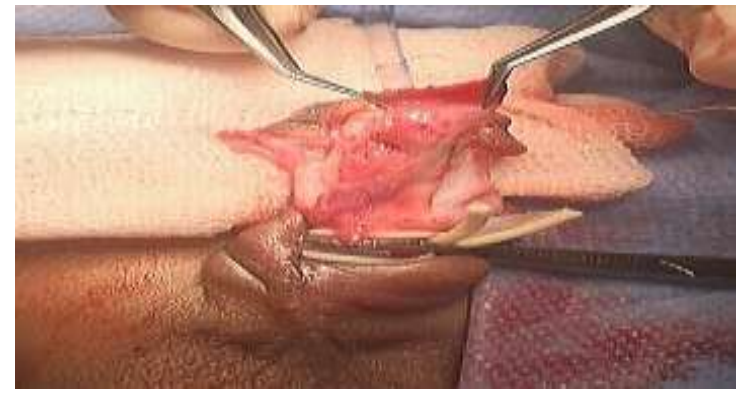

Fig.5 Complete covering by dartos flap

- Oral Cephalosporin's 3rd generation (cefexime) until catheter removed or for 5 days

- Oral or syrup non-steroidal anti-inflammatory drugs like ibuprofen, voltarin.

- Local antiseptic (Bovidon - Fusidin ointment Tetracycline ointment)

- Dressing with sterile dressing

- The patient after 7 days post-operative

\section{Results}

All our 23 patients had primary distal hypospadias and without any associated congenital anomalies, where underwent surgical repair using (TIP)repair [Snodgrass technique ]as mention before, during the period from [ May 2018 to November 2020] in Benha teaching hospital, department of general surgery The preoperative finding regarding local examinations was as following:

Table (1) Showing Penis, Abnormal meatus, Urethral plate, Glans, Scrotum.

Penis

\begin{tabular}{lc}
\hline size & $3.5-4 \mathrm{~cm}$ \\
circumcision & Un circumcised \\
foreskin & available \\
Penile curvature(chordee) & No chordee \\
\hline
\end{tabular}

\section{Abnormal meatus}

\begin{tabular}{lc}
\hline site & Coronal or distal shaft \\
shape & Different abnormal shape \\
size & $2-5 \mathrm{~mm}$ \\
\hline
\end{tabular}

\section{Urethral plate}

\begin{tabular}{lc}
\hline shape & Shallow and some are deep \\
width & $3-5 \mathrm{~mm}$ \\
length & $5-10 \mathrm{~mm}$ \\
\hline
\end{tabular}

\section{Glans}

\begin{tabular}{lc}
\hline shape & Conical, splayed \\
Transverse glans diameter & $8-30 \mathrm{~mm}$ \\
\hline
\end{tabular}


Scrotum

\begin{tabular}{lc}
\hline Undescended testis & Not present \\
Testicular size & Average size \\
\hline
\end{tabular}

All patients included in this study were assisted during, immediately and at 1, 3,6,12 months postoperatively and we found: Regarding the time of the operation it ranges from (70 to 90 minutes). For assessment of the penile curvature and chordee we use the artificial erection method, most of the cases was without chordee from the beginning but doing it to find the simple superficial chordee . Regarding hospital stay post operatively range from (4-24 hours). Regarding complications post operatively from total 23 patients in this study was as the following:

Table (2) postoperative complications following distal hypospadias repair.

\begin{tabular}{lc}
\hline Number of the patients & Complications \\
\hline 1 & fistula \\
1 & Skin infection \\
1 & Unsatisfying cosmetic appearance according to the parents \\
\hline
\end{tabular}

So in this study the risk of the fistula is about $4.3 \%$, and the cosmetic appearance was so acceptable in 22 patient out of 23 which is very convincing result from this simple technique. Glans dehiscence hadn't occur, Meatal stenosis hadn't occur, Skin infection occurred in one patient because he neglect the post-operative follow up visits and bad hygiene so the wound was moisture and infected, Edema, Inflammation and Encrustations. These are simple complications that could occur temporarily. Bladder Spasm and Catheter Blockade: usually occurs from the indwelling urethral catheter.Urethral Stricture wasn't reported in this study. Twisting of the penis is not reported in this study.

\section{Discussion}

Hypospadias is one of the most common congenital malformations in male newborns, Surgical treatment is necessary and more than 300 operation techniques have been described for primary hypospadias, whoever the ultimate goal of hypospadias surgery is to create a normal looking penis with a terminally situated conical meatus, correct chordee if present and to ensure a welldirected, straight, and full urinary stream in the standing position [1].

Snodgrass TIP procedure. It was based on the idea that a midline incision into the urethral plate widens and extends it deeply through the entire urethral plate and found it could be tubularized without using additional skin flaps and heals without stricture. [4]

In this study, Evaluation of Ventral Dartos Fascia Flap as a covering layer in TIP (Tubularized Incised Plate) Repair for Distal Hypospadias cases [Snodgrass Technique] regarding the simplicity, time of operation, complications and its outcome to some of the famous methods for correction of distal hypospadias cases.

Mathieu described a single-stage (meatal $\neg$ based flap technique) to repair the distal forms of hypospadias. The most important problems were :

- A higher incidence of meatal stenosis.

- Tech $\neg$ nical problems related to the coverage of the large ventral skin defect.
- fistula [5].

Thiersch-Duplay technique. Choosing this technique depends on the size and quality of the urethral plate. If the urethral plate is wide and healthy, it can be Tubularized by this technique, but if it is too narrow plate it can't be tubularized using this method ,However the Snodgrass TIP repair in such cases is too sufficient technique with more simplicities, less hospital stay and less complication [4].

Flip-flap technique or meatal-based flap technique (modification of Mustarde's operation). A triangular glanular flap is prepared from the middle third of the glans, but the disadvan $\neg$ tages of this technique were:

- The characteristic conical appearance of the glans.

- An ugly $\neg$ looking meatus

- May interfering with vascularity of the flap [5].

MAGPI procedure (meatal advancement and glanuplasty) it is not generally applicable to all forms of distal hypospadias. The operation time and hospital stay are longer, and higher complication rate [6].

The lateral-based skin flap is not a totally new method of repair. Hadidi, in 2004, studied 49 patients with severe hypospadias who underwent repair using this techni $\neg$ que. Satisfactory results were achieved in 43 (88\%) of the 49 patients ,comparing to using Snodgrass TIP repair it was easy ,simple with satisfactory result up to $(98 \%)$ [6].

A number of series for evaluating TIP urethro $\neg$ plasty between 1994 and 1999 found an overall com $\neg$ plication rate of $5.5 \%$, and the reported outcomes of TIP are en $\neg$ couraging, with complications noted in $15-24 \%$ of all patients [2].

By this study the actual risk of fistula was $4.3 \%$ which is good result comparing to studies from 1994 to 2004 there were 26 published series from centers worldwide comprising 2035 patients. Of these, 181 (9\%) developed complications including fistulas (5\%) [6].

Meatal Stenosis may occur from postoperative edema and adhesion, or a faulty in the procedure. But it is not noticed in this study. Leaving a stent and the frequent application of an ophthalmic ointment at the meatus would sufficient to reduce this complication. Manual dilatation or otherwise meatoplasty may be needed if 
such a condition is well established, most study shown about $5 \%$ of its complication rate [7].

The success rate of this study is about $92 \%$ comparing to $98 \%$ in multicenter reports

So over all the ventral dartos flap method comparing to the dorsal dartos flap is very simple method that take less operative time and its easy, simple with less complications rates .

It has rich vascularized flap opposite to the dorsal dartos flap that may interfere with the vascularity of the skin of the dorsum of the penis .

Also it has no twisting complication regarding the penis.

\section{Conclusion}

Ventral Dartos Fascia Flap as a covering layer in TIP urethroplasty for Distal Hypospadias Patients repair [Snodgrass Technique] is a good procedure with no more complications than other procedures used in hypospadias surgery for distal and midshaft hypospadias patients. With an accepted cosmetic outcome, fast procedure and no complexity also this approach maximizes the utilization of the prepuce in the repair by providing a barrier layer for the urethroplasty from one perpetual half, and a well-vascularized flap to cover the ventral shaft of the distal hypospadias cases with no twisting complication of the penis.

\section{References}

[1] M.R.Zaontz and G.E.Dean. Glanular hypospadias repair. Urol. Clin., Vol. 29, PP.291-298, 2002.

[2] W.T.Snodgrass , A.Lorenzo. Tubularized incised plate urethroplasty for hypospadias reoperation," BJU Int.Vol. 89,PP.98-100, 2002.

[3] N.Djakovic, J.Nyarangi-Dix, A. Özturk Hypospadias," Adv. Urol., Vol. 2008(1), PP.349-398, 2008.

[4] W.Snodgrass.Tubularized, incised plate urethroplasty for distal hypospadias.J. Urol., Vol. 151, PP.464$465,1994$.

[5] A.J.Ibanga , H. B. Ibanga. Psychological Issues in Paediatric Surgery. Paediatric Surgery: A Comprehensive Text for Africa. Global Help. 2011. Vol. 2, PP.233-277,2015.

[6] A.T.Hadidi. Functional urethral obstruction following tubularised incised plate repair of hypospadias," J. Pediatr. Surg. Vol. 48,PP.1778-1783, 2013.

[7] C. L. Secrest. Repair of the complications of hypospadias surgery," J. Urol., Vol. 150, PP.1415$1418,1993$. 